\title{
Novos Phaneropteridae do Brasil
}

\author{
S. DE TOLEDO PIZA
}

Escola Superior de Agricultura "Luiz de Queiroz" Universidade de São Paulo

\section{INDICE}

Ischyra brasiliensis sp. n. $\ldots \ldots \ldots \ldots \ldots \ldots \ldots 90$

Homotoicha precaria sp. n. ...........91

Euceraia rufithorax sp. n. ...........93

Euceraia sanguinea sp. n. ............ 94

Euceraia bos sp. n. ............... 96

Ceraia laminata sp. n. ............. 97 
Ischyra brasiliensis sp. n. (Fig. 1)

Mas. Viridis, subnitidus. Vertex convexiusculus, fastigio modice deflexo, antice quam postice angustiore, articulo primo antennarum sesqui latiore, in medio late sulcato necnon sulco vix impresso utrinque praedito, apice indistincte bituberculato, cum fastigio frontis contiguo sed a sulco transverso secto. Fastigium frontale subtriangulare, apice rotundato, ocello permagno ornatum. Pronotum transversaliter sulcatum, disco inaequali, minutissime et densissime puncturato, margine antico in medio late dentato, margine postico rotundato, in medio rotundatim inciso, lobis deflexis rotundatim insertis, perpendicularibus, altioribus quam longioribus. Elytra elongata, subparallela, translucida, a venulis reticulata, apice rotundata, granulis parvis, eburneis, precipue ad campum anticum et prope venas radiales ornata, ramo primo venae radialis posticae cum vena ulnari a venula transversa connecto, ante medium furcato, ramulis curvis prope originem divergentibus deinde convergentibus, marginem posticum independenter attingentibus, ramulo postico prope medium cum vena ulnari a venula transversa conjuncto. Pars proximalis venae plicatae modice obliqua, ad basin vix crassior. Femora omnia pilosa, antica et intermedia haud sulcata, inermia, postica sulcata, spinis parvulis extus quam intus numerosioribus ornata. Mesosternum acute, metasternum obtuse angulatim lobata. Lamina subgenitalis carinata, postice vix recurva, stylis parvulis, cylindricis praedita. Cerci graciles, modice incurvi, pillosi, apice rotundato, minutissime dentato. Lamina supraanalis longior quam latior, sulcata, apice rotundato, inter cercos perpendiculariter deflexa.

Longitudo corporis .............21,0 mm

Longitudo pronoti $\ldots \ldots \ldots \ldots \ldots \ldots, 5,0 \mathrm{~mm}$

Longitudo elytrorum ........... $36,5 \mathrm{~mm}$

Latitudo elytrorum ante medium ... $9,0 \mathrm{~mm}$

Longitudo femorum posticorum -... 17,4 mm

Pátria :- Manaus, E. do Amazonas.

Col. : Parko, VII-1941.

Tipo: Um: macho pertencente ao Museu Nacional, presentemente na coleção do autor.

Parátipos: Dois machos da mesma procedência capturados juntamente com o tipo e um macho bem maior que os precedentes colecionado no Ribeirão do Engenho, Vale do Itauna, E. do Espírito Santo, por Travassos \& Santcs, em 9-X-1942. 


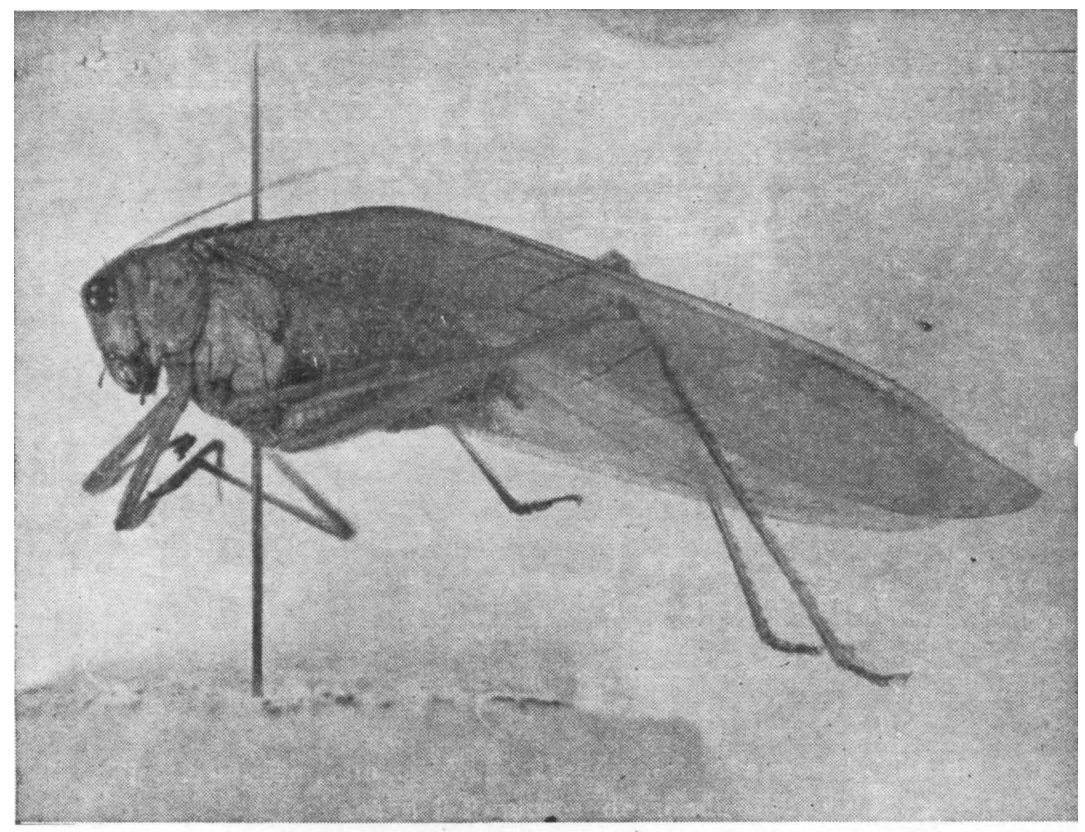

Fig. 1 - Ischyra brasiliensis Piza 
Difere de Ischyra puntinervis Brunner pelos élitros mais estreitos, pelo fastígio do vértice apenas mais largo que o primeiro artículo antenal, pelo bordo posterior do disco pronotal entalhado no meio e pelos fêmures anteriores e médios não sulcados e inermes, os anteriores mais delicados que em punctinervis.

Difere de Ischyra flaviceps Brunner pela forma dos élitros, pelo disco do pronoto de margem anterior dentada, margem posterior entalhada e margens laterais arredondadas e pelos fêmures pilosos.

Difere de Ischyra frutetorum Sauss. et Pict. pelo fastígio frontal năo inciso, pelo pronoto de margem anterior dentada e margem posterior incisa no meio, pelos élitros não pontuados, pela ramificação posterior do ramo radial não confluindo com a veia ulnar e sim a ela ligada por uma vênula transversal mais ou menos longa e pelos lobos mesosternais agudos, porém não ovais.

Difere de Ischyra vepretorum Sauss. et Pict., de que parece muito afim, pelo pronoto muito mais curto e dentado no bordo anterior e pelas numerosas granulações ebúrneas dos élitros.

\section{Homotoicha precaria sp. n. (Fig. 2)}

Mas. Viridescens, partim rufescens. Vertex convexiusculus, fastigio wix deflexo, modice sulcato, apice valde angustiore, cum fastigio frontis haud contiguo. Frons pallida, fastigio acute triangulari. Discus pronoti viridis vel ferrugineo-rufus vel ocraceus, antice quam postice paulo angustior, concavus, plus minusve distincte marmoratus, margine antico truncato, postico rotundato, marginibus lateralibus rufescentibus vel saltem dilutioribus. Lobi deflexi rotundatim insert $i$, longiores quam altiores, subperpendiculares, margine antico modice sinuoso et quam margo posticus sat longiore, margine inferiore propter hoc sat obliquo. Elytra elongata, subparallela, venis venulisque expressis rugosa, minute reticulata, apice rotundato, ramo radiali ante medium oriente, pone medium furcato, viridia, subnitida, translucida, maculis fuscis, parvulis, dilutis, inter venas longitudinaliter seriatis ornata, vena ulnari posteriore et margine postico plus minusve rufescentibus. Tibiae omnes rufescentes. Femora antica et intermedia subtus inermia. Femora postica gracilia, viridia vel distaliter rufescentia, inferne spinis 1-3 ad marginem internum, nullis ad marginem externum. Mesosternum rectangulatim, metasternum rotundatim lobata. 
Segmentum anale in medio vix emarginatum. Lamina subgenitalis elongata, attenuata, ultra medium incisa, lobis inferne sulcatis, stylis teretibus vel subtus sulcatis instructa. Cerci ad basin crassi, teretes, puncturato-granulati, pilosi, extreniitatem versus sinuosi, extus convexiusculi, intus depressi vel concavi, apice truncato, spiculo nigro, parvulissimo, in medio coronae pilorum brevium sito, prope basin processu magno, fortiter incurvo, adunco, apice nigro, intus piloso, basi triangulariter compresso, armati.

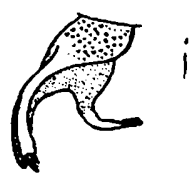

a

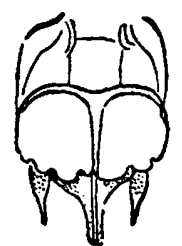

Fig. 2-Homotoicha precaria sp. $n$.

a) Cerco do macho; b) extremidade do abdômen da fêmea visto pela face ventral.

Femina mari similis. Lamina subgenitalis magna, in medio longitudinaliter, ad basin transversaliter fortiter carinata, margine postico rotundato-dentatim sinuoso. Ovipositor pronoto vix longior, ad basin fortiter recurvus, apice, parte distali marginis postici et dimidia parte distali marginis antici crenulatis. Cerci conici, apce longe-acuminato.

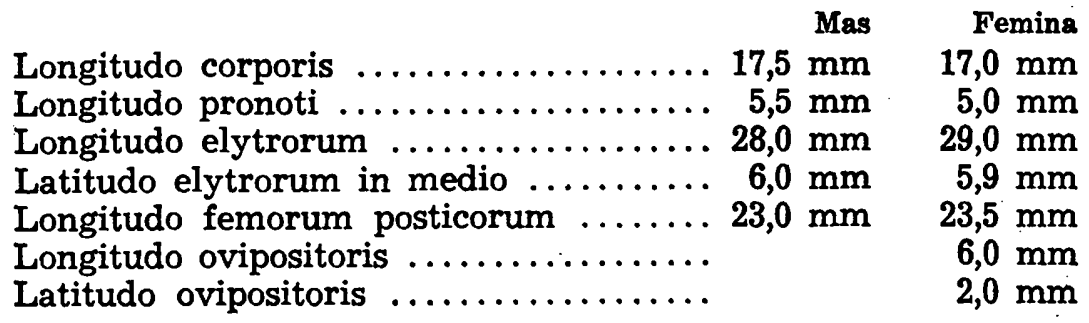

Pátria : E. de São Paulo.

Col.: Camponez, bairro da Jiboia, Piracicaba, VIII-1949 (um macho e uma fêmea); Lordello \& Camponez, bairro da Jiboia, Piracicaba, IX-1949 (dois machos e uma fêmea); Hempel, Bofete, II-1939 (um macho).

Tipos : 4 machos e 2 fêmeas, no laboratório do autor.

Difere de Homotoicha fuscopunctata Caudell pelo colorido, pelos élitros com manchas muito mais numerosas, pelos lobos laterais do pronoto mais longos que altos, pelos fêmures posteriores um pouco mais breves e com 1-3 espinhos no bordo in- 
terno da face ventral. Caudell (Proc. U. S. Nat. Mus. V. XXX, 1906, pag. 236), na breve descrição da fêmea que serviu de base à sua espécie, não faz menção alguma à placa subgenital, a qual, caso se assemelhasse à descrita na presente espécie, não poderia ter passado sem uma referência especial.

Os cercos e a lâmina subgenital do macho, descritos e figurados por Rehn (Proc. Acad. Nat. Sc. Philadelphia, V. LIX, 1907, pag. 376), coincidem com o que foi assinalado na presente espécie. Faltando, porém, qualquer outra informação, não posso resolver sôbre a verdadeira situação do exemplar de Rehn com relação à espécie descrita neste trabalho.

\section{Euceraia rufithorax sp. n. (Fig. 3)}

Mas. Virescens. Caput cinereo-viride. Antennae castaneae, articulis basalibus I et II cinereo-viridibus. Occiput convexum, castaneo-rufum, nitidum, fastigio conico, subsulcato, apice obtuso, cum fastigio frontis haud contiguo. Pronotum disco nitido, antice subtruncato, postice rotundato, prozona et mesozona rufescentibus, metazona rufa, lobis deflexis rotundatim insertis, modice divergentibus, paulo altioribus quam longioribus, ocraceo-virescentibus, nitidis, margine inferiore fortiter

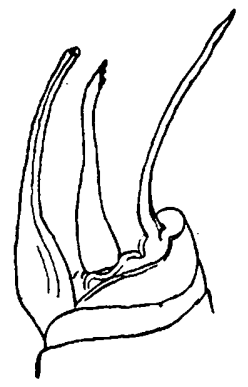

Fig. 3 - Euceraia rufithorax sp. $n$.

Extremidade do abdômen do macho

rotundato. Elytra membranacea, translucida, nitida, venis transversis ac venulis sat expressis, subparallela, apice rotundato, area dorsali ad basin nigricanti. Femora unicoloria, viridia, anteriora subtus spinis 4 parvulissimis, apice nigris, aegre notatis, ad marginem anticum praedita, intermedia spinis similibus 5 , postica spinis majoribus 12 utrinque armata, lobis genicularibus spinosis. Tibiae anticae supra spina parvulissima infra dilatationem tympanorum, altera in medio marginis anticipraeditae, membrana tympanica nigricanti. Mesosternum lobis triangularibus, metasternum rotundatis. Segmentum anale 
truncatum, superne in medio triangulariter compressum, utrinque appendicem longissimam, gracilem, recurvam, apice acutam, inferne ad dimidiam partem distalem sulcatam, haud incrassatam, longitudine pronoti paulo brevioram gerens. Cerci cylindro-conici, graciles, elongati, vix sinuosi, apice mucronati. Lamina subgenitalis angusta, elongata, subparallela, apice triangulariter emarginata, stylis parvulis armata.

Longitudo corporis $\ldots \ldots \ldots \ldots \ldots \ldots 21,0 \mathrm{~mm}$

Longitudo pronoti $\ldots \ldots \ldots \ldots \ldots \ldots, 5,5 \mathrm{~mm}$

Longitudo elytrorum ............ $34,0 \mathrm{~mm}$

Latitudo elytrorum in medio ...... $9,0 \mathrm{~mm}$

Longitudo femorum posticorum .... 21,2 mm

Long. appendicis segmenti anali ... $5,0 \mathrm{~mm}$

Pátria : Vale do Itauna, Ribeirão do Engenho, E. do Espírito Santo.

Col.: Travassos \& Santos, 9-X-1942.

Tipo: Um macho pertencente ao Museu Nacional, presentemente na coleção do autor.

A espécie parece-me bastante afim de Euceraia rufovariegata (Chopard) da qual se distingue pelo colorido e sobretudo pela ausência de pontos difusos vermelho-escuros alinhados nos élitros, cujo àpice não é escuro, pela presença de espinhos no bordo anterior da face ventral dos fêmures anteriores e médios e pela forma dos cercos, que são alongados e delgados:

\section{Euceraia sanguinea sp. n. (Fig. 4)}

Mas. Luteo-virescens, rufo variegatus. Caput omnino fere sanguineum. Vertex convexiusculus, fastigio haud sulcato, apice tuberculato, cum fastigio frontis haud contiguo.Fastigium frontale haud sanguineum, apice modicissime bituberculatum, ocello magno, concolore, praeditum. Antennae sanguineae. Pronotum disco sanguineo, inaequali, nitido, postice quam antice latiore, margine antico truncato, postico in medio subrecto, lateraliter modice rotundato, lobis deflexis rotundatim insertis, perpendicularibus, vix altioribus quam longioribus, haud sanguineis, marginibus rotundatis. Elytra coriacea, subtranslucida, venis et venulis luteo-virescentibus dense reticulata, ramo radiali ante medium oriente, ante medium furcato, ramulo postico a venula obliqua cum vena ulnari anteriore conjuncto, vena plicata elongata, claviformi, valde expressa, margine postico, venis 


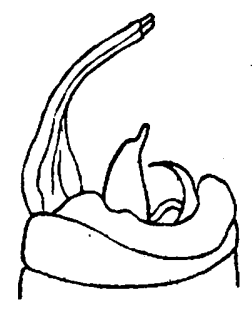

Fig. 4 - Euceraia sanguinéa sp. $n$.

Extremidade do abdômen do macho

nonnullis campi praeradialis, basi campi dorsalis, vena plicata cum ramulis, vena ulnari posteriore, apice postice; maculis crescentibus a basi versus extremitatem secundum venas radiales et marginem posticum dispositis, plus minusve dense sanguineis. Pedes antici coxa antice, magna parte trochanteris, femore omnino, basi et apice tibiae, tarsoque sanguineis necnon femore inferne ad marginem anticum spinis nigris 4-5 armato, tibia superne spinis 4 postice praedita. Pedes intermedi femore ad apicem, tibia basi et apice, tarsoque sanguineis, femore subtus spinis 1-3 ad marginem anticum, tibia superne spinis 6 ad marginem posticum. Pedes postici parte proximali femoris valde crassiore, parte media et apice late sanguineoanulatis, parte ventrali spinis 6-7 intus, 7-8 extus armata, lobis genicularibus bispinosis; tibia basi et apice sanguineis, necnon anulis 2 latis, sanguineis in medio ornata; tarso sanguineo. Mesosternum triangulariter, metasteurnum rotundatim lobata. Segmenta abdominalia partim sanguinea. Segmentum anale partim sanguineum, truncatum, superne in medio depressum, inferne appendicibus duabus brevibus, gracilibus, acutissimis, convergentibus et tangentibus, sanguineis, praeditum. Cerci breves, crassi, vix arcuati, sanguini, ad extremitatem dente valido, curvo, apice nigro, armati. Lamina subgenitalis elongata, curvata, extremitatem versus ampliata, truncata, stylis cylindricis paulo longioribus quam crassioribus instructa.

Longitudo corporis . ............ 26,0 mm

Longitudo pronoti $\ldots \ldots \ldots \ldots \ldots \ldots, 6,0 \mathrm{~mm}$

Longitudo elytrorum ........... $38 ; 0 \mathrm{~mm}$

Latitudo elytrorum ............ $9,0 \mathrm{~mm}$

Longitudo femorum posticorum ... 27,0 mm

Pátria : Benjamin Constant, E. do Amazonas.

Col. : Parko, III-1943.

Tipo: Um macho pertencente ao Museu Nacional, presentemente com o autor. 
A espécie difere pelo colorido, pelo segemento anal, pelos cercos e pela lâmina subgenital, das outras espécies conhecidas do gênero.

\section{Euceraia bos sp. n. (Fig. 5)}

Mas. Virescens. Vertex subplanus, fastigio sulcato, cum fastigio frontis haud contiguo. Frons lutescens, fastigio anguste triangulari, apice acuto, rufo maculato, ocello permagno praedito. Genae cinerescentes: Oculi magni, rotundati. Appendices oris partim rufescentes. Antennae articulis basilaribus flavis, apice angustissime rufo anulatis. Pronotum lutescens, puncturato-ruguloso impressum, disco antice convexiusculo, postice plano, margine antico truncato, postico rotundato, lobis
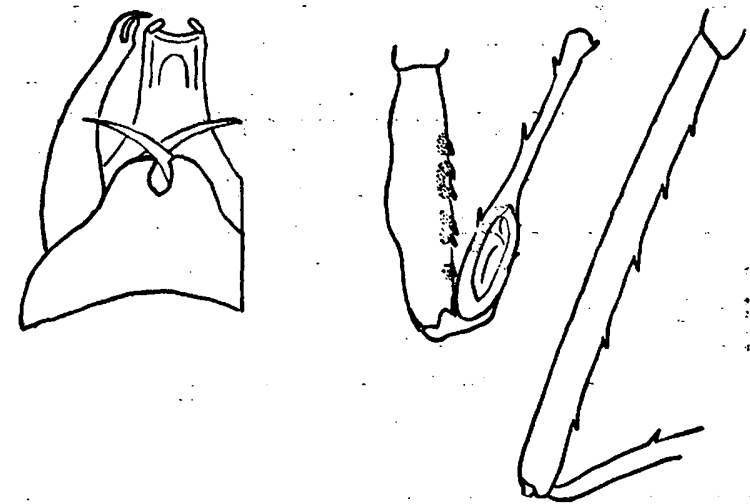

Fig. 5 - Euceraia bos sp. $n$. Extremidade .do abdômen, fềmur e tibia anteriores e tibia intermédia do macho

deflexis vix altioribus quam longioribus, rotundatim insertis, haud perpendicularibus, marginibus rotundatis. Elytra viridia, ad basin inter venas radiales et venam ulnarem posteriorem lutescentia, marginibus parallelis, apice rotundato, ramo radiali paulo ante medium oriente, post medium furcato, ramulo postico cum vena ulnari anteriore confluente. Pedes antici coxis cum spinis coxalibus rufescentibus, trochanteribus omnino fere rufescentibus, extus nigro-nitido maculatis,- femoribus crassis, compressis, rufescentibus, nitidis, superne et antice undulatis, inferne ad marginem anticum spinis dentiformibus nigris 5 in maculis nigris armatis, margine postico sat prominenti, 
utrinque omnino fere nigro, tibiis basi rufescentibus, dilatata, dimidia parte distali dilatationis nigra, parte reliqua virescenti, superne postice spina parvulissima ad dilatationem, inferne spinis 3-3 armatis. Femora intermedia virescentia, inferne spinis 5, apice nigris, ad marginem anticum armata. Femora postica intus spinis 7, extus 9-10 instructa. Mesosternum lobis triangularibus praeditum, metasternum lobis rotundatis. Segmentum anale postice rotundatim profunde divisum, lobis ungui bovis similibus, inferne appendicibus duabus acutissimis, introrsum directis armatum. Cerci crassi, modice arcuati, extremitatem versus attenuati, apice in mucronem recurvum et processum sinuosum diviso. Lamina subgenitalis brevis, paulo attenuata, margine postico rotundato, stylis parvulis instructo.

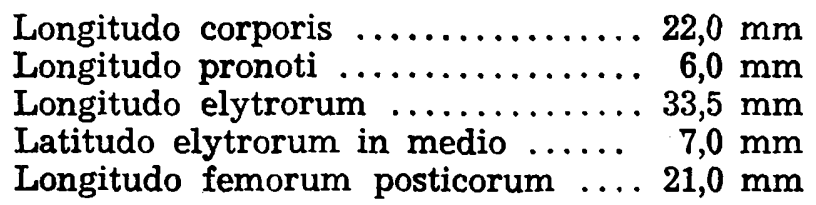

Pátria : Manaus, E. do Amazonas.

Col.: Parko, VII-1941.

Tipo: Um macho pertencente ao Museu Nacional, atualmente com o autor.

A presente espécie assemelha-se muito a Euceraia femorata (Chopard) descrita de um macho da Guiana Francêsa. Difere pelo colorido, pelos fêmures anteriores providos de verdadeiros espinhos dentiformes e não de tubéculos espiniformes, implantados em manchas negras, de bordo posterior da face ventral quase inteiramente negro de ambos os lados e não apenas provido de uma mácula negra, pelos fêmures intermédios espinhosos na margem anterior da face ventral, pela forma dos lobos do segmento anal e pelos cercos robustos e não muito alongados e fendidos no ápice.

\section{Ceraia laminata sp. n. (Fig. 6)}

Mas. Viridis. Caput lutescens a pronoto modice constrictum, vertice convexiusculo, fastigio sulcato, apice obtuso, cum fastigio frontis contiguo. Oculi magni, paulo prominentes. Labrum vinaceum, in medio obscurius. Fastigium frontis angustum. Articuli antennarum basales virides, sequentes nodulosi, nodulis obscure vinaceis. Pronotum antice et postice aequelatum, disco viride-zebrato, margine antico subtruncato, postico rotundato, lobis deflexis perpendicularibus, altioribus quam 
longioribus, rotundatim insertis, marginibus rotundatis. Elytra elongata, parallela, apice rotundata, fortiter reticulata, maculis parvis ferrugineis inter venas alineatis vel dispersis ornata, ramo radiali ante medium oriente, longe post medium furcato, ramulo postico cum vena ulnari anteriore haud connecto. Femora antica et intermedia subtus inermia, femora postica spinis validis, vinaceis, apice nigris, extus 5 , intus 8 , armata. Tibiae anticae basi vix dilatata, superne vinacea, membrana tympani vinacea, partim nigricanti, praeter spinam apicalem spinis duabus ad marginem posticum, una in medio, altera in basi dilatationis armatae. Tibiae intermediae superne spinis 5-6 postice instructae. Mesosternum triangulariter, metasternum rotundatim lobulata, discis dilute ferrugineis. Segmentum anale postice in medio appendicibus duabus brevibus, folia-

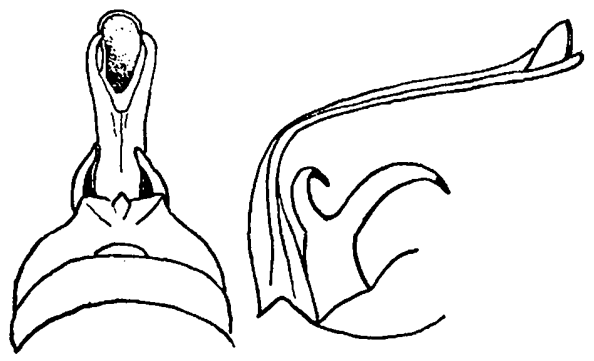

Fig. 6 - Ceraia laminata sp. $n$. Extremidade do abdômen do macho vista por cima e por um dos lados

ceis sed in processus conicos modice arcuatos longitudinaliter plicatis, inter quos dente parvo praeditum. Cerci validi, dense granulati, biramosi, ramis arcuatis, mucronatis, ramo superiore quam ramus inferior valde crassiore et longiore. Lamina subgenitalis elongata, angusta, apicem versus vix ampliata, sursum fortiter recurva, laete vinacea, inferne concava, superne prope extremitatem convexa, apice triangulariter concavo, margine postico rotundato-truncato, stylis nullis.

Longitudo corporis $\ldots \ldots \ldots \ldots \ldots 23,0 \mathrm{~mm}$

Longitudo pronoti $\ldots \ldots \ldots \ldots \ldots \ldots, 6,0 \mathrm{~mm}$

Longitudo elytrorum .......... $38,0 \mathrm{~mm}$

Latitudo elytrorum in medio ..... 7,0 mm

Longitudo femorum posticorum ... 27,0 mm

Pátria : Piracicaba, E. de S. Paulo.

Col. : A. Zamith, V-1950.

Tipo: Um macho na coleção do autor.

Difere das espécies afins pela forma do segmento anal, da lâmina subgenital e dos cercos. 